Research Article

Honglei Xie, Hai Fang*, Wei Cai, Li Wan, Ruili Huo, and David Hui

\title{
Development of an innovative composite sandwich matting with GFRP facesheets and wood core
}

https://doi.org/10.1515/rams-2021-0016

Received Dec 15, 2020; accepted Dec 29, 2020

\begin{abstract}
This paper presents the concept, design, fabrication, application and experimental validation of a new type of composite sandwich matting. The composite sandwich matting comprises a paulownia woods as core material and glass fiber reinforced plastic (GFRP) as face-skins and lattice-webs. The matting was fabricated by vacuum infusion moulding process (VIMP). The mechanical properties of the component materials were studied. Four-point bending tests were also performed to investigate the flexural properties of the paulownia wood core sandwich panels. The experimental results showed that the failure mode of the structures was upper facesheet compressive yielding. The structures have good integrity against transverse load, there was a large plateau region after the initial failure and can prevent the structures from catastrophic failure. The finite element (FE) analysis showed a good agreement with the experimental results in predicting the loaddisplacement curve. The developed composite sandwich matting has been successfully used in military engineering, emergency rescue and large infrastructure construction owing to its excellent mechanical properties.
\end{abstract}

Keywords: paulownia wood, sandwich matting, GFRP

\section{Introduction}

Sandwich structures have been widely used in civil engineering, construction, marine and aerospace owing to their advantages of high bending stiffness, low structural weight

\footnotetext{
^Corresponding Author: Hai Fang: Advanced Engineering Composites Research Center, Nanjing Tech University, Nanjing 211816, China; Email: fanghainjut@163.com

Honglei Xie, Wei Cai: College of Civil Engineering, Nanjing Tech University, Nanjing 211816, China

Li Wan, Ruili Huo: Advanced Engineering Composites Research Center, Nanjing Tech University, Nanjing 211816, China

David Hui: Department of Mechanical Engineering, University of New Orleans, New Orleans, LA 70124, United States of America
}

and good environmental resistance [1-6]. The structures comprise two relatively thin facesheets against in-plane tension and compression stress, and a light weight core material mainly bears shear stress. In the past, innovative design and structural concept using FRP sandwich composites have been demonstrated in structural roofing, walls and bridge decks [7-9]. The structures also drew a lot of interest in the military field. Because the traditional matting such as AM-2, M19 are very heavy, complicated, time consuming, and need numerous pieces of support and maintenance equipment [10]. It is difficult to implement logistical support quickly and effectively because of the widespread use of advanced weapons in a war. Severe environmental and ground conditions often limit the rapid mobility of combat and service forces, as well as the rapid construction of engineering facilities such as airports, positions, helipads, and warehouses. It is critical to make provision for rapid repairs and emergency rescue by constructing temporary transportation facility. Sandwich structures provide the feasibility to meet military contingency requirements due to their excellent mechanical properties [10-12]. Therefore, it is essential to investigate the mechanical behaviors of sandwich structures.

Siivola et al. [13] noticed that the initial failure was facesheets tensile yielding at the edges of the foam core sandwich beams. Three point bending test were performed by Borsellino et al. [14] to understand the effects of various skin arrangement on the fracture mechanisms of the PVC foam core composite structures, the effects of various skin arrangement were also studied. Wood was found to be a potential core material due to its advantages of significant environmental benefits, excellent mechanical behaviors and easy to be manufactured [15-18]. Qi et al. [19] studied the bending properties of sandwich beams with paulownia wood or southern pine wood core. Their test results revealed that the main failure modes of wood-core sandwich beams were core shearing, facesheet compressive and local wrinkling failure. A balsa core sandwich decks were proposed by Keller et al. [20] and have been successfully used in Avançon Bridge. New design methods were also proposed to fulfil the requirements of ultimate states and fatigue. Shi et al. [21] carried out four-point flexural and

Ә Open Access. (c) $2021 \mathrm{H}$. Xie et al., published by De Gruyter. (CC) BY This work is licensed under the Creative Commons Attribution 4.0 License 
fatigue tests and found that GFRP-balsa sandwich beams were dominated by the core shearing and debonding failure. Steeves and Fleck [22, 23] constructed failure mode maps to reveal the failure mechanism of sandwich structures. The proposed analytical model can accurately predict the facesheet microbuckling, core shearing and facesheet indentation failure.

Zhou et al. [24] placed carbon fiber and glass fiber rods into the foam core before fabricating sandwiches to improve the energy absorbing characteristic of the structures. Yalkin et al. [25] studied the mechanical behaviors of sandwich composites with stitched or perforated foam core. Compressive, flexural, shear and impact tests were conducted. The test results showed that the proposed stitched or perforated foam core can significantly improve the mechanical performances of the structures. However, these methods are time-consuming and lab-intensive, and all require special equipment to assist in processing. They may not be available to fabricate large components. It is critical to study a new family of sandwich structures to meet the requirements of rapid fabrication, installation and contingency operations.

In this paper, an innovative sandwich matting composed of GFRP facesheets and paulownia wood core was designed and introduced, which can be used to construct or repair the road in a short time to conduct contingency operations. The composite sandwich matting was integrally fabricated through the vacuum infusion moulding process (VIMP). When the composite sandwich matting subjected to transverse load, the inner lattice-webs can enhance the interfacial bonding performance can prevent the structure from debonding failure, and the paulownia wood provides elastic supports for the matting to avoid local buckling. The manufacturing process, experimental investigations and finite element analysis were also studied for its wide range of applications in civil engineering and military engineering.

\section{Composition of GFRP-paulownia wood sandwich matting}

This section presents the properties of the constituent materials and geometry dimensions of the composite sandwich matting. Besides, details of specimen preparation and installation are introduced.

\subsection{Material properties and manufacturing}

The materials used in the sandwich matting were 3-layer E-glass non-woven fabric with fiber orientation of $(0$, $\left.90^{\circ}\right) /\left( \pm 45^{\circ}\right) /\left(0,90^{\circ}\right)$ and an areal density of $800 \mathrm{~g} / \mathrm{m}^{2}$, paulownia wood with a density of $290 \sim 300 \mathrm{~kg} / \mathrm{m}^{3}$, and vinyl resin (HS-2100). Vinyl resin was chosen due to its excellent chemical resistance, durability, ease of processing and relatively low cost. The thickness of the matting can be chosen according to the actual design requirements. In this study, the total thickness of the matting was $120 \mathrm{~mm}$, and the paulownia wood core was $110 \mathrm{~mm}$ in thickness. Geometry dimension of the matting was $4230 \times 1060 \times 120$ $\mathrm{mm}^{3}$, and the thinner parts of four edges were $60 \mathrm{~mm}$ in thickness (Figure 1). The interface bonding performance of facesheets and core was considerably improved by the use of GFRP lattice-webs, the surface skin and the core are closely bound by the lattice-webs (Figure 1). The edges of the matting in the longitudinal direction were equipped with 5 connection holes, and the edges of each short side were equipped with only 1 connection hole. Moreover, there was " $\mathrm{V}$ "-shape ribs on the upper surface of the matting with a height of $2.5 \mathrm{~mm}$ and a length of $120 \mathrm{~mm}$, which can increase the wear resistance of the structures. The density of the composite sandwich panels was much lower than that of concrete or steel, with a density of $2400 \mathrm{~kg} / \mathrm{m}^{3}$, which is desirable in civil applications and contingency operations. Figure 1(b) shows the construction sketch map of the composite sandwich matting.

The manufacturing process of the sandwich matting is as follows (Figure 2): (i) prepared paulownia wood before

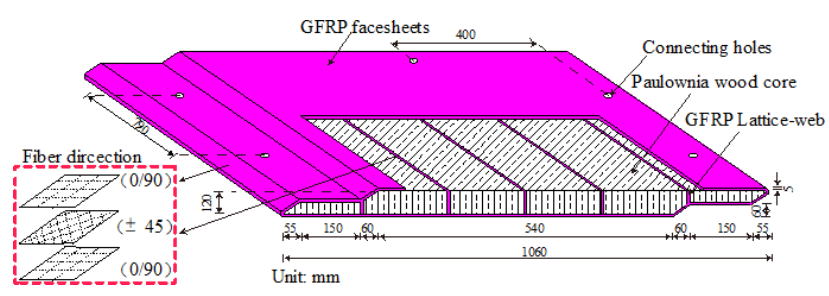

(a)

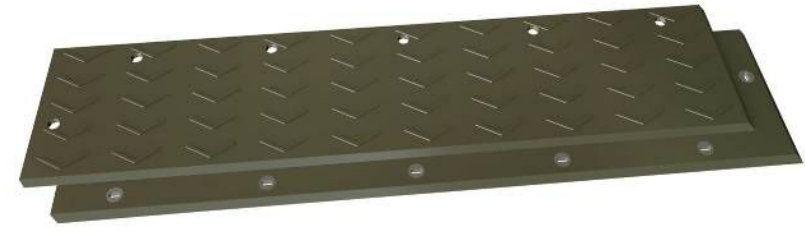

(b)

Figure 1: Specific geometry dimensions of composite sandwich matting with total thickness of $120 \mathrm{~mm}$. (a) geometry dimensions of the section view, (b) sketch map of the composite sandwich matting. 


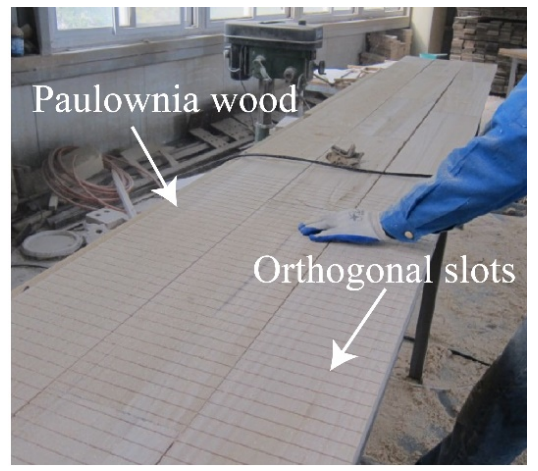

(a)

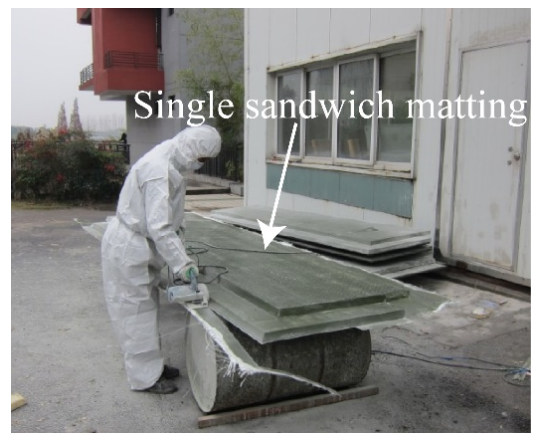

(d)

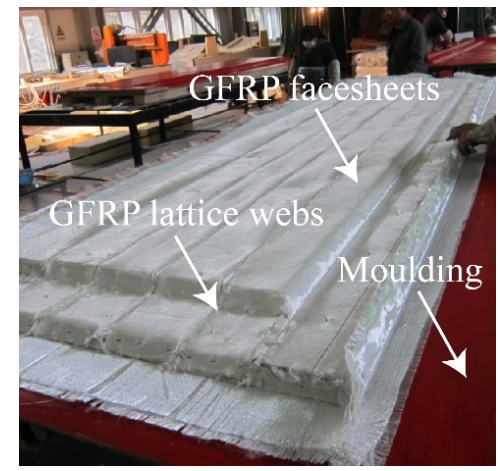

(b)

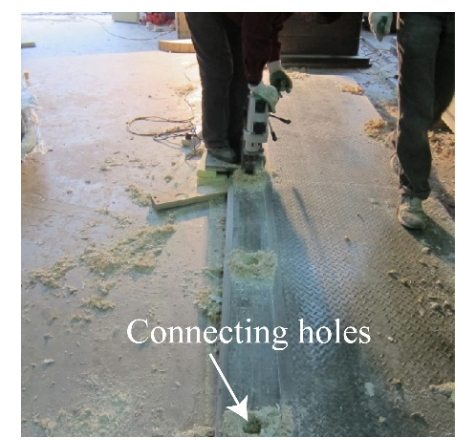

(e)

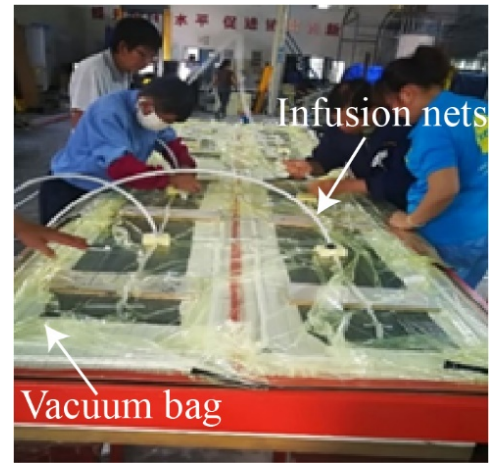

(c)

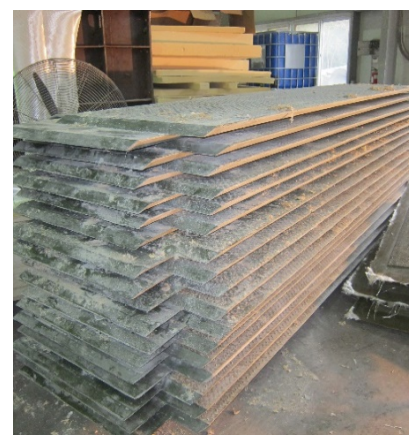

(f)

Figure 2: Fabrication process of the sandwich matting. (a) prepared the paulownia wood core, (b) glass fabric to wrap the prepared core, (c) VIMP, (d) demolding, (e) drill the holes, (f) photo of the fabricated sandwich matting.

manufacturing. Paulownia wood was selected to fabricate core strips by cutting into six pieces along the direction of the texture; (ii) created orthogonal slots (with a depth and width $2 \mathrm{~mm}$ ) on the upper and lower surfaces, to provide flow channels for resin without obviously weakening the performance of the core; (iii) cut the glass fabric into appropriate size, and then used a layer of glass fabric to wrap the prepared core material; (iv) place two layers of glass fabric on the mold, and then place the wrapped paulownia core into the mold, finally, place two layers of glass fabric on the upper face of the wrapped paulownia core; (v) arrange the vacuum consumable materials; (vi) injected the resin into the vacuum bag and cured for 24 hours at room temperature.

\subsection{Matting installation}

The composite matting system is composed of a lot of paulownia wood sandwich panels. When an emergency occurs, soft clay site conditions are difficult to meet the driving requirements of vehicles, and personnel cannot carry out basic operations on this site, let alone complete military tasks. The designed composite sandwich matting can be used for rapid construction and repair of roads under soft clay site conditions, as presented in Figure 3(a). Each full-scale matting was installed according to the guideline, the soft soil was firstly surfaced with sandwich matting by hand when the layout is determined. Then the connection of the long dimension is through one steel connectors, as presented in Figure 3(b), aligning the prefabricated connecting holes. Simple cam-lock connection pieces will be embedded into the prefabricated holes requiring only the mating piece to secure the panel together. The next row was placed mating the thinner end together with the adjacent panels, aligning the prefabricated connecting holes, the short dimension ends were connected by five steel connectors to ensure effectively load transfer to prevent eccentric instability failure during vehicle loading. All the connectors can be installed and removed manually, which is of great convenience for construct temporary transportation facilities.

The matting can be quickly assembled by human actions without additional machinery. Two people can easily move it. For example, a workplace with area of $5000 \mathrm{~m}^{2}$ can be assembled or disassembled by 6 people in only 12 
hours. Similarly, a road with length of $500 \mathrm{~m}$ can be paved by 4 people in only 8 hours. The number of employment and the operation time range from one-seventh to one-fifth of that of the conventional way.

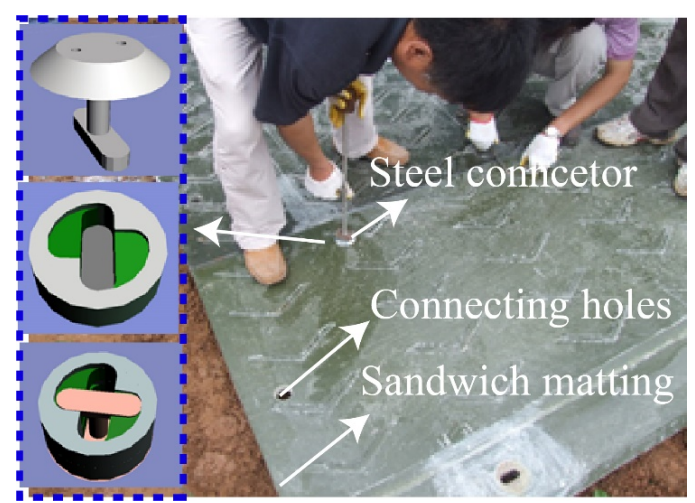

(a)

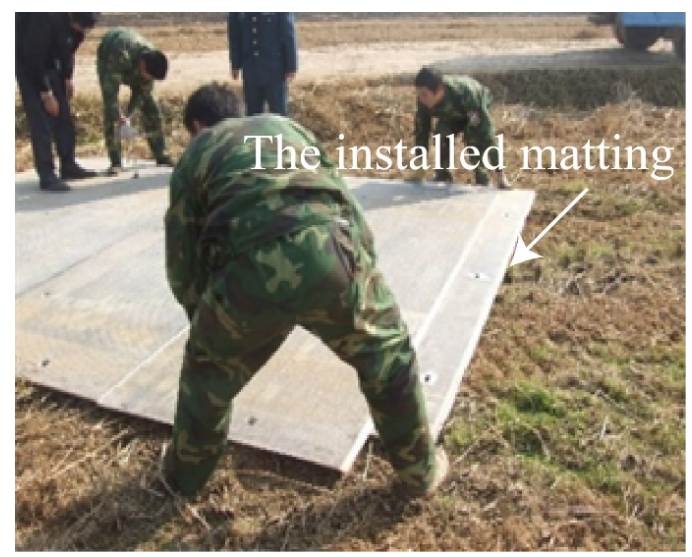

(b)

Figure 3: The installation of sandwich matting. (a) install sandwich matting, (b) the platform for vehicle driving.

\subsection{Materials Characterization}

In order to obtain the mechanical behavior of GFRP facesheets, tensile tests were carried out according to ASTM D3039 (Figure 4(a)) [26]. A group of 8 GFRP samples with fiber stacking sequence of $[0 / 90,-45 / 45,0 / 90]$ were tested. The samples were tested on the CMT 5205 universal testing machine under a displacement control rate of $2 \mathrm{~mm} / \mathrm{min}$. The obtained experimental results were listed in Table 1. The GFRP samples were soaked into the saturated $\mathrm{NaCl}$ solution for 3, 10, 15, and 30 days. Then, tensile experiments were conducted on these specimens. The obtained tensile strength and elastic modulus of the 30-day soaked specimens were $282.20 \mathrm{MPa}$ and $19.76 \mathrm{GPa}$, respectively. It can be concluded that the tensile strength of soaked specimens decreased slightly ( $7.5 \%$ decreased) while the elastic modulus remained unchanged compared to those unsoaked specimens, indicated that the GFRP facesheets have a better corrosion resistance can be used in harsh conditions.

Compressive tests were also conducted on the GFRP coupons according to ASTM D3410 under a displacement control rate of $1 \mathrm{~mm} / \mathrm{min}$ (Figure 4(b)) [27]. The shear tests were carried out by off-axis $45^{\circ}$ tensile tests according to ASTM D3518 using German Zwick/Roell Z050 electronic testing machine (Figure 4(c)) [28]. A group of 3 GFRP samples was tested.

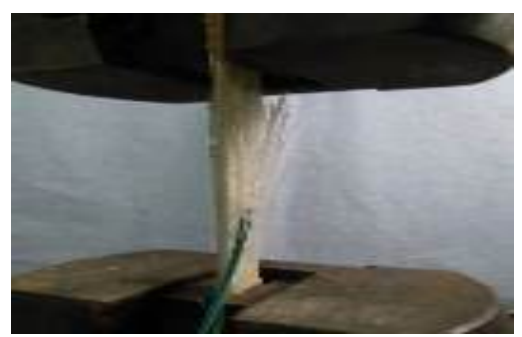

(a)

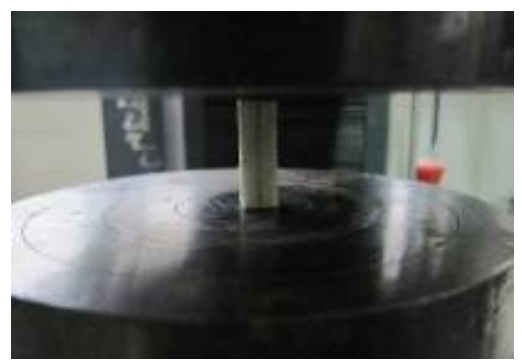

(b)

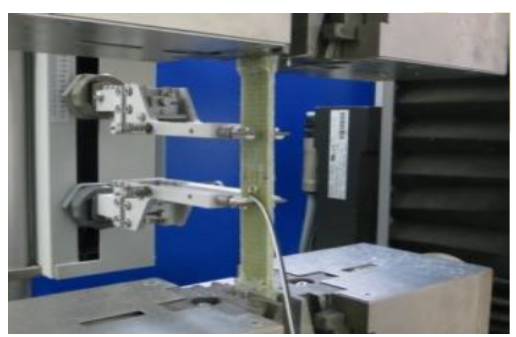

(c)

Figure 4: GFRP material test set-up: (a) tensile test (b) compressive test (c) shear test.

Compressive tests and shear tests were carried out to characterize the mechanical properties of the paulownia wood and poplar wood core according to ASTM C365 and ASTM C273 (Figure 5) [29, 30], respectively. The detailed experimental results were listed in Table 1. A group of 3 GFRP samples was tested. 
Table 1: Mechanical properties of GFRP ply and paulownia wood core.

\begin{tabular}{ccccc}
\hline Property & & GFRP & Paulownia wood & Poplar wood \\
\hline Compressive & Compressive strength(MPa) & 51.82 & 26.53 & 40.52 \\
\multirow{3}{*}{ Tensile } & Compressive modulus(GPa) & 12.03 & 5.67 & 7.92 \\
& Tensile strength(MPa) & 305.00 & - & - \\
\multirow{3}{*}{ Shear } & Tensile modulus(GPa) & 20.35 & - & - \\
& Shear strength(MPa) & 22.21 & 3.34 & 4.21 \\
& Shear modulus(GPa) & 5.37 & 0.32 & 0.50 \\
\hline
\end{tabular}

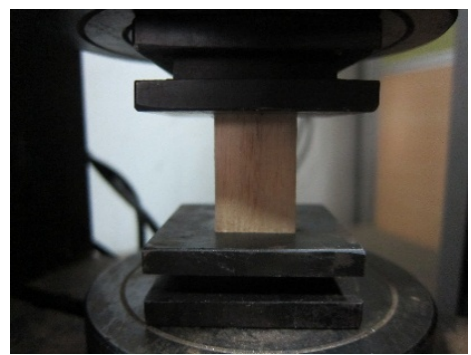

(a)

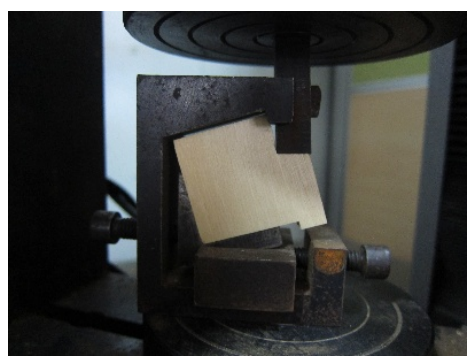

(b)

Figure 5: Test set-up of wood material: (a) compressive test (b) shear test.

\subsection{Four-point bending tests}

The single sandwich matting was simplified into a 1700 $\times 120 \times 125 \mathrm{~mm}^{3}$ sandwich panel (Figure 6). Four-point bending tests were performed to evaluate the bending properties of the sandwich panels. In accordance with ASTM

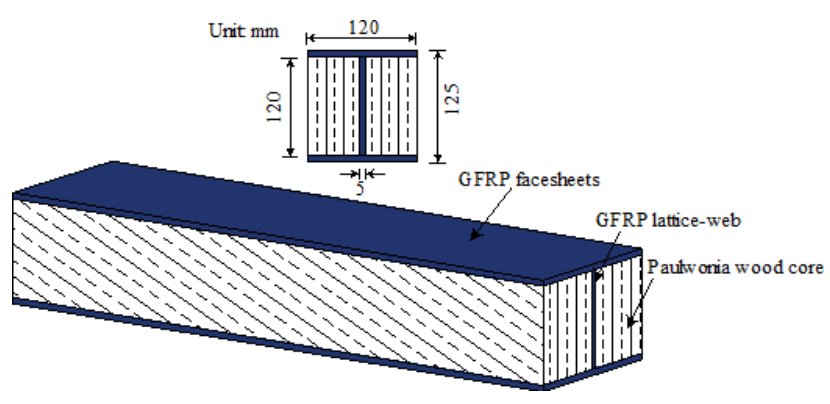

Figure 6: Sketch of the specimen web reinforced pawuownia wood sandwich panel.
D7264 [31], the experiments were performed until the failure of sandwiches at a displacement rate of $2.0 \mathrm{~mm} / \mathrm{min}$ and force versus displacement curves were recorded using a universal testing machine. The four-point flexural test set-up was shown in Figure 7, the third point loading span configuration (i.e., 4-point third span) with total span of $1500 \mathrm{~mm}$. During the tests, the loading rollers with a diameter of $30 \mathrm{~mm}$ were provided under the steel plates to prevent premature failure. To obtain the relationship of loading and displacement, a vertical displacement gauge was attached to the bottom facesheet at the middle span of the composite sandwich plates and until final failure. Electrical resistance strain gauges with a resistance of $120 \Omega$ were attached to the upper and lower facesheet.

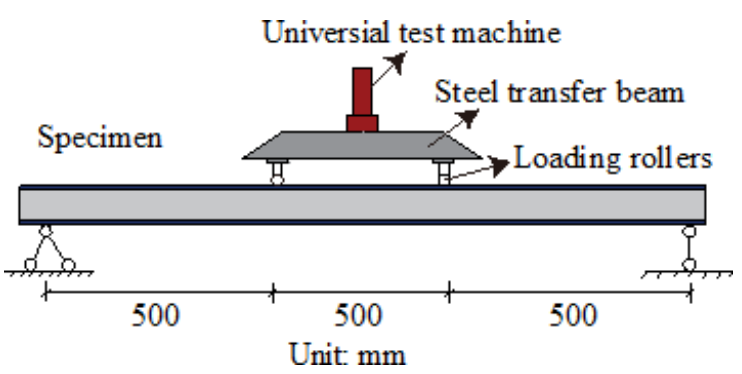

(a)

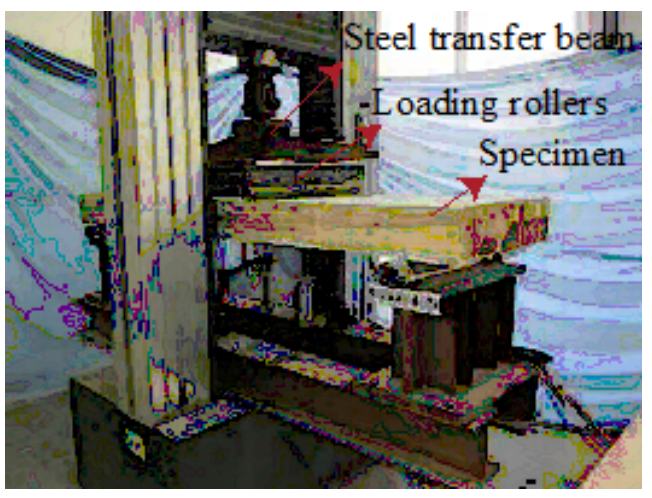

(b)

Figure 7: Four-point bending test set-up of sandwich panel: (a) schematic illustration of flexural of sandwich panel (b) experimental set-up. 


\section{Structural design}

The design of composite sandwich structure is the overall process of material selection and size optimization to achieve predetermined optimization goals (such as cost, weight, strength, stiffness). There are many variable factors involved, such as the selection of component materials (foam or paulownia core material, fiber cloth, resin matrix), the size control of the core material and the panels. Among the variable factors, the core materials have different reinforcement methods and the fiber panels have various layup directions. Therefore, it is difficult to summarize the optimal sandwich structure design method. In this study, simple and feasible optimization design methods based on strength and rigidity requirements were proposed for reference in engineering practice.

Generally, facesheet yielding, core shear and compressive failure dominated the failure of sandwich panels. It was assumed that the GFRP facesheet and paulownia wood core exhibited linearly up to the failure.

\subsection{Compressive/Tensile failure of the facesheet}

Under four-bending tests, the upper facesheet of the structure is subjected to compressive stress and the lower facesheet is subjected to tensile stress. Compressive or tensile failure of the facesheet occurred when shi The ultimate load of this failure mode [32]

$$
F s 1=\frac{12 E I \sigma f}{L E f(t c+2 t f)}
$$

in which $E I$ was the equivalent flexural stiffness of the structure; $\sigma f, E_{f}$ were the compressive strength and compressive modulus of the GFRP facesheet, respectively; $t_{c}, t_{f}$ were the thickness of the paulownia wood core and GFRP facesheet, respectively. The equivalent flexural stiffness of the structure is [18]

$$
E I=E_{f} \frac{b t_{f} d_{f}^{2}}{2}+\frac{b t_{c}^{3}\left(E_{c} t_{w}+2 E_{f} a\right)}{24 a}
$$

in which $b$ is the width of the specimen, $t_{w}$ is the thickness of the lattice-web, $E_{c}$, is the modulus of the core, $a$ is the spacing of the lattice-web. In this study, the calculated equivalent flexural stiffness of the selected specimen is $8.14 \times 10^{11} \mathrm{~N} \cdot \mathrm{mm}^{2}$.

\subsection{Shear failure of the core}

Core shear failure occurred when the shear stress exceed the shear strength of paulownia wood core. The ultimate load of this failure mode [33]

$$
F c 1=2 \tau_{c} b H+2 \Sigma \tau_{w} t_{c}\left(t w+\frac{G_{c} b c}{G_{w}}\right)+4 \tau_{w} b t_{f} \frac{G_{c}}{G_{w}}
$$

in which $G_{c}$ and $G_{w}$ denote the shear modulus of the wood core and GFRP, $\tau_{c}$ and $\tau_{w}$ denote the shear modulus of the wood core and GFRP, $t_{w}$ and $b_{c}$ denote the width of GFRP web and wood core, respectively.

\subsection{Compressive/Tensile failure of the core}

Core tensile or compressive failure occurred when the normal stress exceed the strength of paulownia wood core. The ultimate load of this failure mode

$$
F c 2=\frac{12 E I \sigma c}{L E c t c}
$$

where $\sigma c, E_{c}$ were the compressive strength and compressive modulus of the paulownia wood core, respectively.

\subsection{Facesheet wrinkling}

Face wrinkling is a local elastic instability of the faces involving short wavelength elastic buckling of the upper facesheet, resisted by the underlying elastic core. It may be viewed as the buckling of a beam in axial compression (the facesheet) supported by an elastic foundation (the core). The ultimate load of this failure mode [22]

$$
F s 2=3 b d \frac{t_{f}}{L} \sqrt[3]{E_{f} E_{c} G_{c}}
$$

\section{Results and Discussion}

The load-displacement curves of wood core sandwich panels were plotted in Figure 8. The label PA and PO represented the paulownia wood and poplar wood core sandwich panels, respectively. The numbers 80 and 120 represented the core thickness of $80 \mathrm{~mm}$ and $120 \mathrm{~mm}$, respectively. It can be seen that the bending properties of sandwich panels showed three regions. For specimen PA-80, the load linearly increased with the increase of displacement to reach the peak load of $159.6 \mathrm{kN}$, the material was in elastic stage, the displacement was $34.8 \mathrm{~mm}$. At the second stage, the load dropped after the elastic stage up to the load of $129.4 \mathrm{kN}$ 


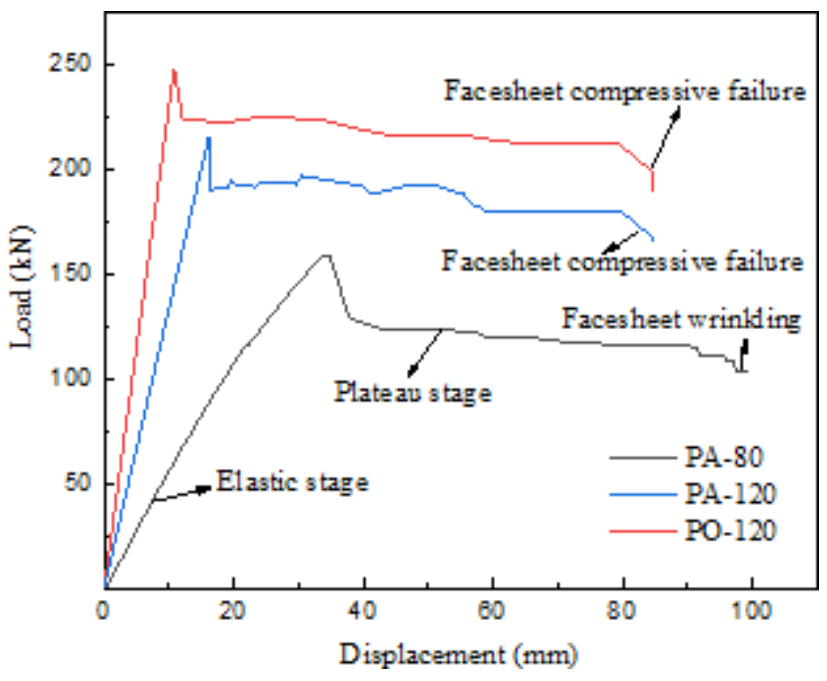

Figure 8: The load-displacement curves of the wood core sandwich panels.

with a displacement of $37.7 \mathrm{~mm}$, which is due to the few fiber breakage of the upper facesheet. Then, the load remains almost unchanged with the increase of displacement until the failure of the facesheet wrinkling (Figure 9(a)). For specimen PA-120, at the first stage (linear elastic), the load linearly increased with the increase of displacement to reach the peak load of $217.0 \mathrm{kN}$, the material was in elastic stage, the displacement was $18.0 \mathrm{~mm}$. At the second stage, the load dropped slightly just after the elastic stage up to the load of $190.0 \mathrm{kN}$, which is due to the few fiber breakage of the upper facesheet, the mid-span displacement remained unchanged was $18.0 \mathrm{~mm}$. In the third region (plateau), the load remain almost unchanged with the increase of displacement until the failure of the top facesheet compressive (Figure 9(b)), the maximum displacement was 86.0 $\mathrm{mm}$. For specimen PO-120, the failure mode (Figure 9(c)) was similar to the specimen PA-120, the maximum load was $225.0 \mathrm{kN}$. The ultimate load of PA-120 was $36.0 \%$ higher than the specimen PA-80. The failure modes from facesheet wrinkling changed into the facesheet compressive breakage. The ultimate load of PO-120 was 3.7\% higher than the specimen PA-120. The sandwich structures with poplar wood core have a higher carrying capacity, however, the density of poplar wood is almost twice that of paulownia wood. Using paulownia as the core material is beneficial to reduce weight without reducing the bearing capacity compared to the poplar wood core. Therefore the paulownia wood with $120 \mathrm{~mm}$ thickness was selected as the sandwich matting core material.

Delamination failure did not occur indicated that the use of lattice webs can significantly improve the bonding performance of core and facesheets. The specimen showed

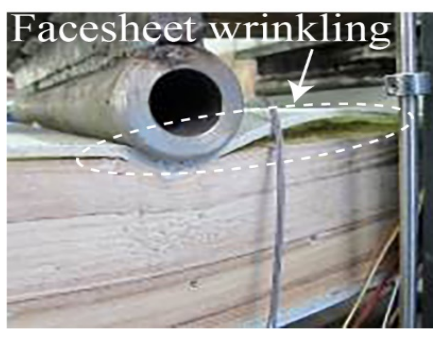

(a)

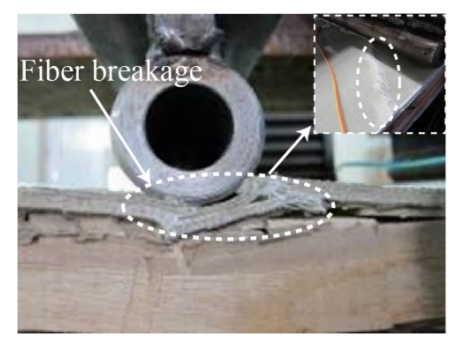

(b)

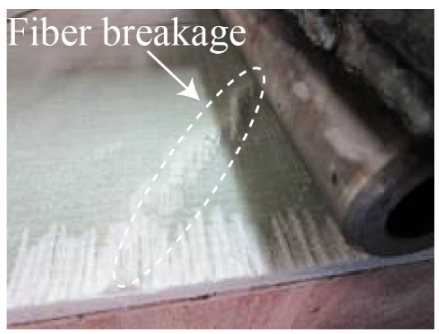

(c)

Figure 9: The failure modes of the wood core sandwich panels. (a) PA-80, (b) PA-120, (c) PO-120.

a large plateau region in the load-displacement curve which is due to the progressive failure of the upper facesheet, indicating the specimen can absorb more energy which is desirable to be applied in civil engineering and military engineering. The absorbed energy of specimen PA-120 during the test can be calculated according to the obtained curve, the absorbed energy was $14.6 \mathrm{~kJ}$. The excellent mechanical behavior of the sandwich panel means that the matting was flexible enough to bear local load and larger plastic deformation, which can prevent the structure from a sudden failure without warning. The internal lattice-web was the key factor to prevent structural delamination and brittle failure. The predicted ultimate loads caused by facesheet compressive failure, core shear, core compressive and facesheet wrinkling failure were calculated according to Eqs. 1-5 were $225,257,384.2$ and $289.9 \mathrm{kN}$, respectively. The theoretical ultimate load of facesheet compressive failure was 3.7\% higher than the experimental failure load, which demonstrated the accuracy of the structural design method. 


\section{Numerical simulation and full-scale tests}

\subsection{Numerical simulation of simplified sandwich panel}

Numerical simulations were carried out to assess the global behavior of the composite sandwich panel by using ANSYD/LS-DYNA commercial software. The SHELL 163 elements were used for the composite material part (facesheets and lattice-web). The continuous shell elements in the 4node demonstrated superior hourglass control and reduced integral while considering the finite membrane strain, the paulownia wood core was regarded as an orthotropic solid element (8-node SOLID 164). Moreover, the contact surface of the paulownia wood core and the GFRP was surfaceto-surface contact pair through cohesive elements, which considered the possible structural failures caused by the

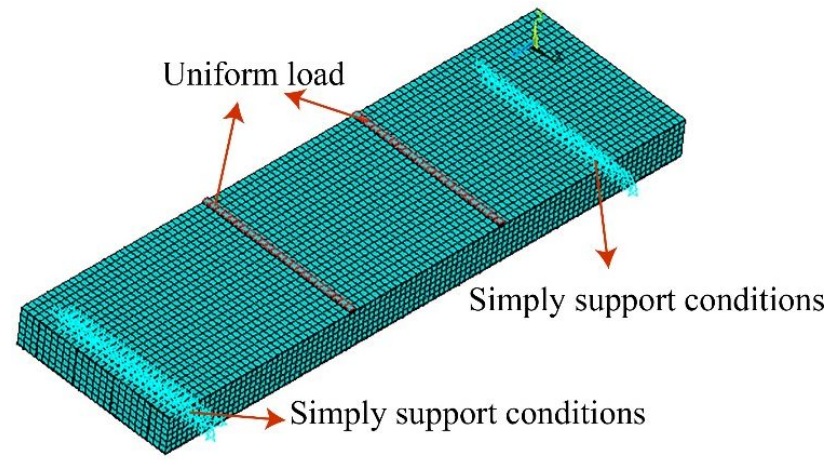

(a)
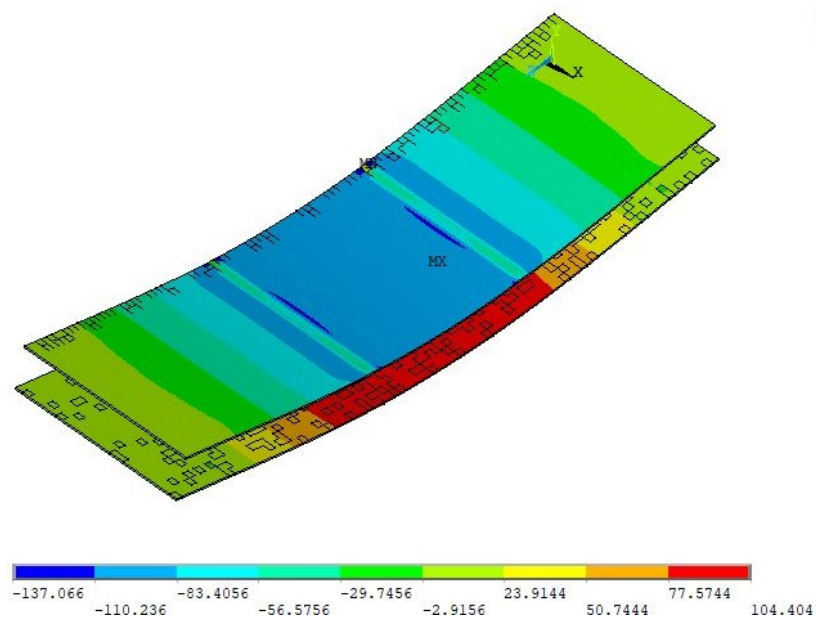

(b)

Figure 10: The model of FEA. (a) meshing and loading setup, (b) the stress of facesheets. debonding of the facesheet and core. The maximum normal traction $T_{\max }$ was $0.5 \mathrm{MPa}$, the stiffness of the cohesive elements was $75.0 \mathrm{MPa} / \mathrm{mm}$, the fracture energy was 1045 $\mathrm{kJ} / \mathrm{m}^{2}$ [34].

Loading and boundary conditions of the overall $\mathrm{FE}$ model for the tested composite sandwich matting were applied in accordance with the experimental tests (simply support conditions), as seen in Figure 10. The material parameters were reported in Table 2 [33]. The load-displacement curve of numerical simulation and four-point bending test result were depicted in Figure 11. It can be observed that the structure exhibited a linear load-displacement relationship before failure. As the deflection increased, the compressive stress on the upper part of the sandwich panel progressively increased, and the tensile stress on the lower part

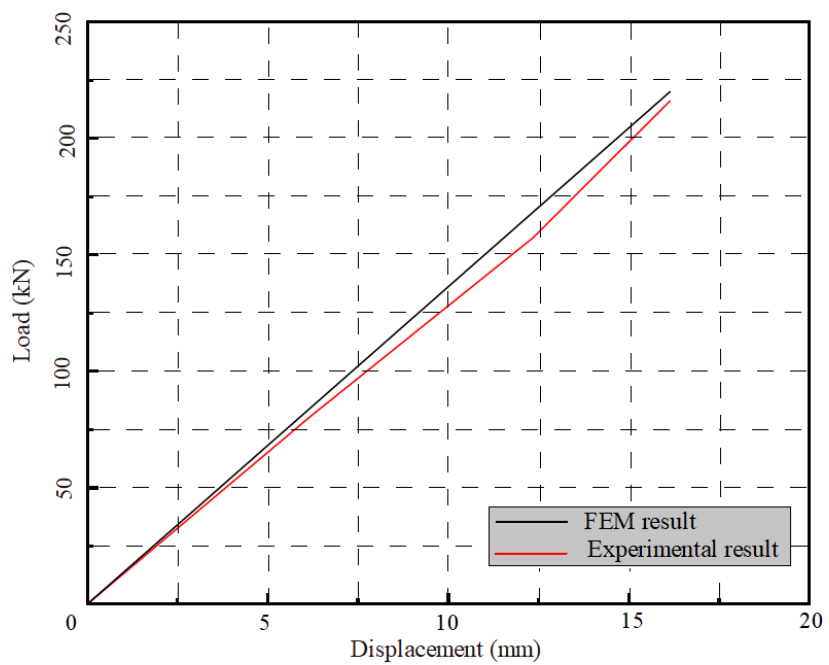

(a)

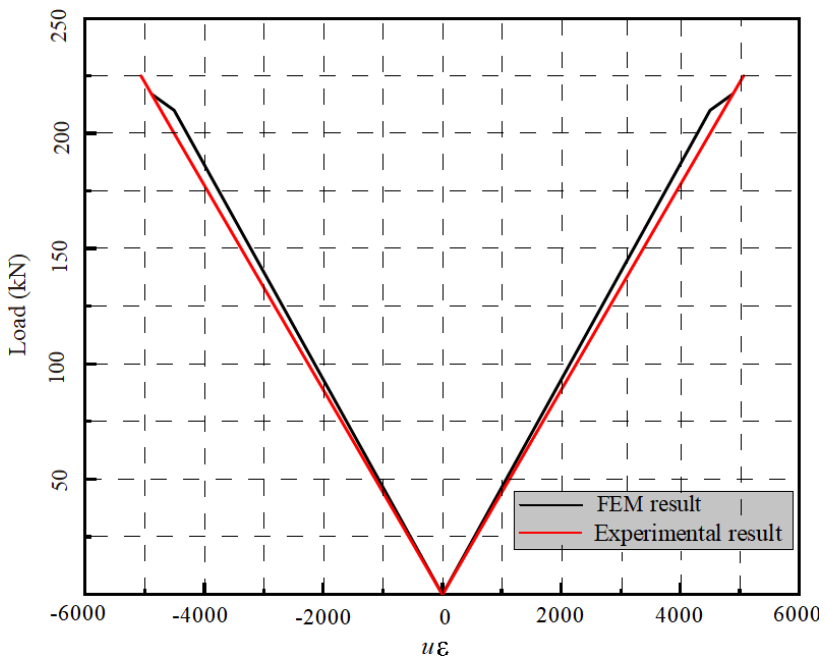

(b)

Figure 11: Comparison between test result and FEA result. (a) loaddisplacement curve, (b) load-strain curve. 
Table 2: Mechanical properties of GFRP and paulownia wood core used in FEM model.

\begin{tabular}{cccccccccc}
\hline Material & $E_{1}(\mathrm{~Pa})$ & $E_{2}(\mathrm{~Pa})$ & $E_{3}(\mathrm{~Pa})$ & $N u_{12}$ & $N u_{12}$ & $N u_{12}$ & $G_{12}(\mathrm{~Pa})$ & $G_{13}(\mathrm{~Pa})$ & $G_{23}(\mathrm{~Pa})$ \\
\hline GFRP & $2.03 \mathrm{e}^{10}$ & $9.52 \mathrm{e}^{9}$ & $9.52 \mathrm{e}^{9}$ & 0.21 & 0.21 & 0.21 & $5.37 \mathrm{e}^{9}$ & $5.37 \mathrm{e}^{9}$ & $5.37 \mathrm{e}^{9}$ \\
$\begin{array}{c}\text { Paulownia } \\
\text { wood }\end{array}$ & $5.67 \mathrm{e}^{9}$ & $1.47 \mathrm{e}^{9}$ & $1.47 \mathrm{e}^{9}$ & 0.23 & 0.23 & 0.23 & $3.20 \mathrm{e}^{8}$ & $3.20 \mathrm{e}^{8}$ & $2.09 \mathrm{e}^{8}$ \\
\hline
\end{tabular}

gradually increased too, the upper and lower equivalent stresses were similar. The good agreements of numerical simulation and experimental results demonstrated that the rationality of facesheet and core cohesive elements contact. In addition, FEM can simulate the responses of the sandwich panel specimens well.

\subsection{Full-scale tests}

The composite pavement panels designed in this article are generally used for rapid repair and construction of roads under soft clay site conditions. The ZL50 wheel loader was used to conduct field on-board tests on the matting, and the whole machine with the weight of $18 \mathrm{t}$, the maximum single-axle weight is about $10 \mathrm{t}$; recorded the deflection of the matting when the wheel load acts on the plate, the side of the plate, and the corner of the plate, the obtained maximum deflection of the matting is about $2 \sim 3 \mathrm{~cm}$. The matting was not damaged, the residual deformation of the matting after unloading is within millimeters, and the node devices can be easily removed and installed after unloading. In addition, vehicle-mounted operating conditions such as trucks and crawler vehicles have been tested. The test results show that the matting can meet emergency needs.

The experiments of fatigue, impact and vibration tests on the full-scale sandwich matting were necessary in the fu- ture for a better application in civil engineering and military engineering.

\section{Application of the composite sandwich matting}

This form of composite sandwich matting has been applied as pavement panels in the military engineering, emergency rescue, large infrastructure construction and applied as the bridge decks.

1. Military application: Conventional construction techniques, such as asphalt and portland cement concrete paving, require considerable resources and time periods that usually inhibit rapid deployment for the military. During warfare, high efficiency military logistics and rapid deployment of military forces are extremely required. To overcome the problems caused by the austere environment and ground conditions, this composite sandwich matting can be used to rapidly construct temporary traffic such as airfields, helicopter parking aprons and warehouses, as shown in Figure 12(a). It can be used for the army to quickly open positions, temporary passages, sites, heliports, and quickly repair various damaged sites to meet

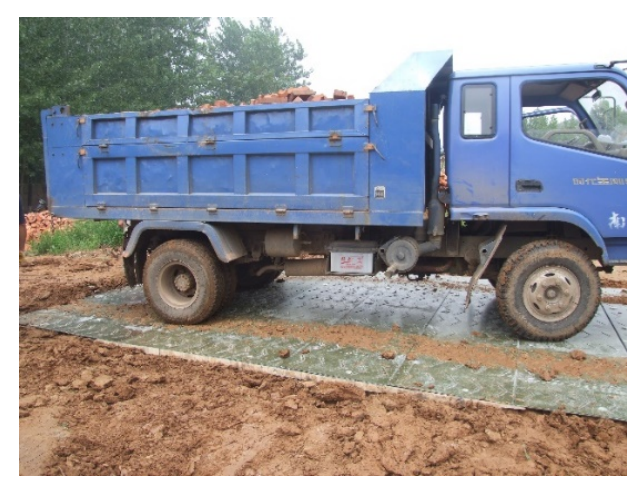

(a)

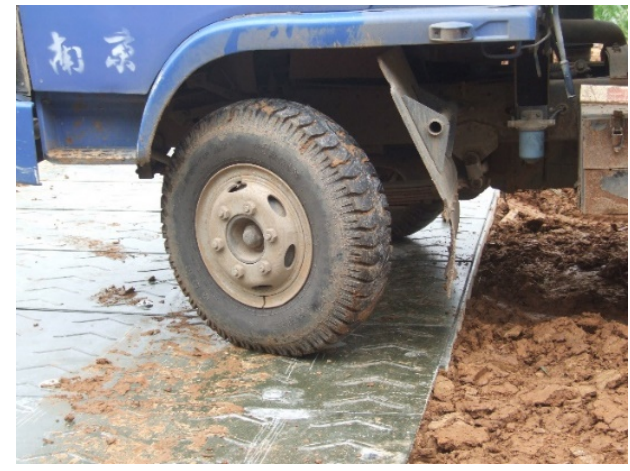

(b)

Figure 12: Full-scale tests of the installed matting: (a) load cart test wheel on the middle of the matting; (b) load cart test at the edge of the matting. 


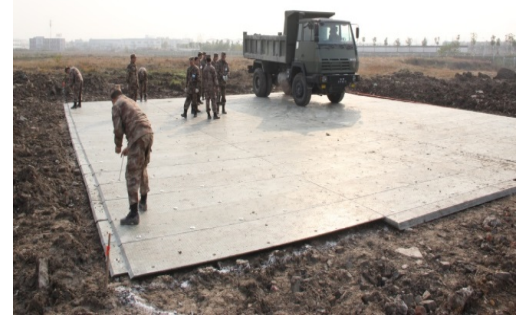

(a)

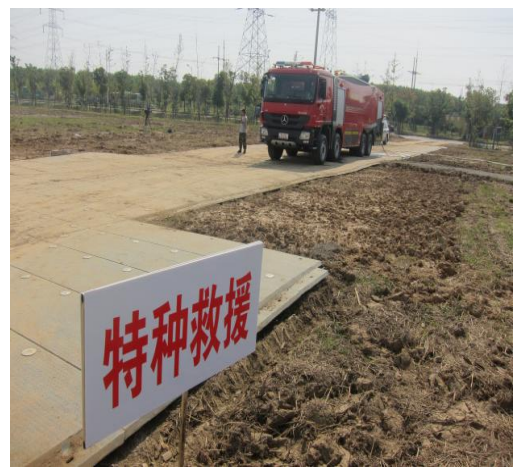

(b)

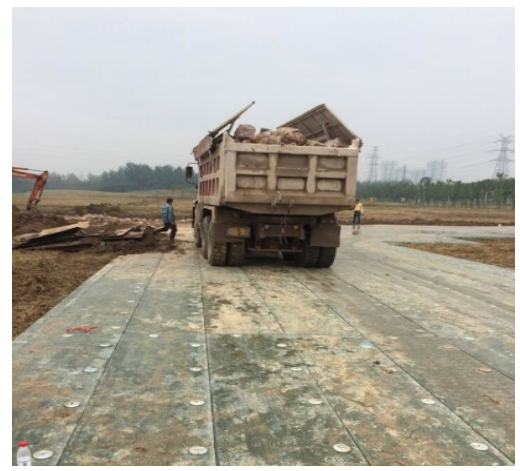

(c)

Figure 13: Application of paulownia wood core composite sandwich matting: (a) military engineering, (b) emergency rescue, (c) oil, natural gas and coal mine project.

the requirements for rapid mobility in combat and logistics support.

2. Emergency rescue and disaster relief: When natural disasters or emergencies occur, highways, bridges, railways and airfields all suffer from tremendous damages, which cut off the lifeline of emergency rescue and disaster relief. In this case, the composite sandwich matting can be applied as temporary traffic facilities to construct temporary roads and fields so that supplies and personnel can be rapidly transferred and precious rescuing time can be ensured. On the other hand, this matting can also be used as the working platform for medical aid and heavy machinery (Figure 12(b)).

3. Oil, natural gas and coal mine project: This form of composite sandwich matting can be assembled into construction site and temporary road for oil, gas and coal mine engineering, which can greatly reduce initial construction costs and can also improve working efficiency, as depicted in Figure 12(c).

\section{Conclusions}

This paper carried out a series of experimental tests on the novel composite sandwich matting for urgent repair and construction in military engineering and civil engineering. The proposed composite sandwich matting consisted of GFRP skins and paulownia wood core. The concept, design, manufacture and experimental validation were described in this paper. The failure modes were discussed. Furthermore, the flexural behavior, stiffness, failure modes, and the load carrying capacity were evaluated. The experimental program has also evaluated the feasibility of the assem- bly progress, and the theoretical analysis and finite element simulation were carried out. The main concluding remarks drawn from the work in this paper are as follows:

1. The sandwich concept consisting of GFRP facesheets and paulownia wood core allowed economic fabrication of the composite sandwich matting, which fulfills all the requirements concerning serviceability, lightweight and high load capacity.

2. Due to the VIMP offers good advantage of high molding efficiency, this fabrication technology can be applied in manufacturing large-scale composite sandwich structure members, as well being able to be used in rapid prototyping of composite sandwich matting. A single matting can be moved and installed by two persons without any special equipment owing to the lightness of the matting, with the length of $4230 \mathrm{~mm}$, width of $1060 \mathrm{~mm}$, the thickness of 125 $\mathrm{mm}$, and weight of $80 \mathrm{~kg}$. Therefore, the assembly and disassembly process can be conveniently and rapidly performed.

3. A FE model was developed to predict the actual behavior of the composite sandwich panel under design loads. The finite element values and experimental results are in good agreement in predicting the loaddisplacement curve.

4. The developed sandwich matting can be applied in military engineer, compaction treatment was no need to be conducted. The matting can be directly paved on silt soil, swamps, wetlands, native grasslands, deserts, shores and can even be applied in permafrost regions, which effectively avoids environmental destruction. 
Conflict of Interests: The authors declare that they have no known competing financial interests or personal relationships that could have appeared to influence the work reported in this paper.

Data availability: The raw/processed data required to reproduce these findings cannot be shared at this time as the data also forms part of an ongoing study.

Founding information: The research described herein was supported by the National Key Research and Development Program of China (2019YFD1101205), the Natural Science Foundation for Distinguished Young Scholars of Jiangsu Province (Grant No. BK20190034), and the National Natural Science Foundation of China (Grant No. 52078248).

\section{References}

[1] Kathavate, V. S., K. Amudha, L. Adithya, A. Pandurangan, N. R. Ramesh, and K. Gopakumar. Mechanical behavior of composite materials for marine applications - an experimental and computational approach. Journal of the Mechanical Behavior of Materials, Vol. 27, No. 1-2, 2018, id. 27.

[2] Manalo, A. C., T. Aravinthan, W. Karunasena, and M. M. Islam. Flexural behaviour of structural fibre composite sandwich beams in flatwise and edgewise positions. Composite Structures, Vol. 92, No. 4, 2010, pp. 984-995.

[3] Wu, Y., B. Tang, K. Liu, X. Zeng, J. Lu, T. Zhang, and X. Shen. Enhanced flexural properties of aramid fiber/epoxy composites by graphene oxide. Nanotechnology Reviews, Vol. 8, No. 1, 2019, pp. 484-492.

[4] Jiang, Q., S. S. Tallury, Y. Qiu, and M. A. Pasquinelli. Interfacial characteristics of a carbon nanotube-polyimide nanocomposite by molecular dynamics simulation. Nanotechnology Reviews, Vol. 9, No. 1, 2020, pp. 136-145.

[5] Li, X., W. Liu, H. Fang, R. Huo, and P. Wu. Flexural creep behavior of web reinforced GFRP-balsa sandwich beams: Experimental investigation and modeling. Composites. Part B, Engineering, Vol. 196, 2020, id. 108150.

[6] Xie, H., L. Wan, B. Wang, H. Pei, W. Liu, K. Yue, et al. An Investigation on Mechanical Behavior of Tooth-Plate-Glass-Fiber Hybrid Sandwich Beams. Advances in Polymer Technology, Vol. 2020, 2020, pp. 1-11.

[7] Keller, T., C. Haas, and T. Vallée. Structural Concept, Design, and Experimental Verification of a Glass Fiber-Reinforced Polymer Sandwich Roof Structure. Journal of Composites for Construction, Vol. 12, No. 4, 2008, pp. 454-468.

[8] Satasivam, S., Y. Bai, and X.-L. Zhao. Adhesively bonded modular GFRP web-flange sandwich for building floor construction. Composite Structures, Vol. 111, 2014, pp. 381-392.

[9] Xue, W. C., and K. Fu. Experimental research on mechanical behaviors of GFRP bridge decks under alkaline solution. Journal of Reinforced Plastics and Composites, Vol. 32, No. 23, 2013, pp. 1835-1841.
[10] Doyle, J. D., I. L. Howard, C. A. Gartrell, G. L. Anderton, J. K. Newman, and E. S. Berney IV. Full-scale instrumented testing and three-dimensional modeling of airfield matting systems. International Journal of Geomechanics, Vol. 14, No. 2, 2014, pp. 161-170.

[11] Garcia, L., and I. L. Howard. Full-scale instrumented testing of multiple airfield matting systems on soft soil to characterize permanent deformation. Transportation Geotechnics, Vol. 9, 2016, pp. 80-95.

[12] Zaman, A., S. A. Gutub, and M. A. Wafa. A review on FRP composites applications and durability concerns in the construction sector. Journal of Reinforced Plastics and Composites, Vol. 32, No. 24, 2013, pp. 1966-1988.

[13] Siivola, J. T., S. Minakuchi, and N. Takeda. Unloading response prediction of indentation loaded foam core sandwich structures using extended foam material model with tensile hardening. Composites. Part B, Engineering, Vol. 84, 2016, pp. 71-82.

[14] Borsellino, C., L. Calabrese, and A. Valenza. Experimental and numerical evaluation of sandwich composite structures. Composites Science and Technology, Vol. 64, No. 10-11, 2004, pp. 1709-1715.

[15] Borrega, M., and L. J. Gibson. Mechanics of balsa (Ochroma pyramidale) wood. Mechanics of Materials, Vol. 84, 2015, pp. 75-90.

[16] Mei, C., Y. Fan, L. Mei, and G. Luo. Surface characteristics of modified poplar wood-flour and its effect on the mechanical properties of wood polymer composites. Reviews on Advanced Materials Science, Vol. 33, 2013, pp. 203-210.

[17] Raftery, G. M., A. M. Harte, and P. D. Rodd. Bond quality at the FRP-wood interface using wood-laminating adhesives. International Journal of Adhesion and Adhesives, Vol. 29, No. 2, 2009, pp. 101-110.

[18] Fan, Y., C. Mei, Y. Liu, and L. Mei. Effect of surface free energy of wood-flour and its polar component on the mechanical and physical properties of wood-thermoplastic composites. Reviews on Advanced Materials Science, Vol. 33, 2013, pp. 211-218.

[19] Qi, Y., H. Fang, H. Shi, W. Liu, Y. Qi, and Y. Bai. Bending performance of GFRP-wood sandwich beams with lattice-web reinforcement in flatwise and sidewise directions. Construction \& Building Materials, Vol. 156, 2017, pp. 532-545.

[20] Keller, T., J. Rothe, J. de Castro, and M. Osei-Antwi. GFRP-Balsa Sandwich Bridge Deck: Concept, Design, and Experimental Validation. Journal of Composites for Construction, Vol. 18, No. 2, 2014, id. 04013043.

[21] Shi, H., W. Liu, and H. Fang. Damage characteristics analysis of GFRP-Balsa sandwich beams under Four-point fatigue bending. Composites. Part A, Applied Science and Manufacturing, Vol.109, 2018, pp. 564-577.

[22] Steeves, C. A., and N. A. Fleck. Collapse mechanisms of sandwich beams with composite faces and a foam core, loaded in threepoint bending. Part I: Analytical models and minimum weight design. International Journal of Mechanical Sciences, Vol. 46, No. 4, 2004, pp. 561-583.

[23] Steeves, C. A., and N. A. Fleck. Collapse mechanisms of sandwich beams with composite faces and a foam core, loaded in threepoint bending. Part II: Experimental investigation and numerical modelling. International Journal of Mechanical Sciences, Vol. 46, No. 4, 2004, pp. 585-608.

[24] Zhou, J., Z. W. Guan, W. J. Cantwell, and Y. Liao. The energyabsorbing behaviour of foam cores reinforced with composite rods. Composite Structures, Vol. 116, 2014, pp. 346-356. 
[25] Yalkin, H. E., B. M. Icten, and T. Alpyildiz. Enhanced mechanical performance of foam core sandwich composites with through the thickness reinforced core. Composites. Part B, Engineering, Vol. 79, 2015, pp. 383-391.

[26] Standard test method for tensile properties of polymer matrix composite materials; ASTM D3039: American Society for Testing and Materials. ASTM, West Conshohocken, PA, 2017.

[27] Standard Test Method for Compressive Properties of Polymer Matrix Composite Materials with Unsupported Gage Section by Shear Loading. ASTM D3039: American Society for Testing and Materials; ASTM D3410, West Conshohocken, PA, USA, 2016.

[28] Standard Test Method for In-Plane Shear Response of Polymer Matrix Composite Materials by Tensile Test of a $\pm 45^{\circ}$ Laminate; ASTM D3410, West Conshohocken, PA, USA, 2018.

[29] Standard Test Method for Flatwise Compressive Properties of Sandwich Cores. ASTM C365. West Conshohocken, PA, 2016.

[30] Standard Test Method for Shear Properties of Sandwich Core Materials. ASTM C273. West Conshohocken, PA, 2016.
[31] Standard Test Method for Flexural Properties of Polymer Matrix Composite Materials. ASTM D7264. West Conshohocken, PA, 2016.

[32] Mostafa, A., K. Shankar, and E. V. Morozov. Experimental, Theoretical and Numerical Investigation of the Flexural Behaviour of the Composite Sandwich Panels with PVC Foam Core. Applied Composite Materials, Vol. 21, No. 4, 2013, pp. 661-675.

[33] Zhu, D., H. Shi, H. Fang, W. Liu, Y. Qi, and Y. Bai. Fiber reinforced composites sandwich panels with web reinforced wood core for building floor applications. Composites. Part B, Engineering, Vol. 150, 2018, pp. 196-211.

[34] Höwer, D., B. A. Lerch, B. A. Bednarcyk, E. J. Pineda, S. Reese, and J.-W. Simon. Cohesive zone modeling for mode I facesheet to core delamination of sandwich panels accounting for fiber bridging. Composite Structures, Vol. 183, 2018, pp. 568-581. 